\title{
Simultaneous Determination of Atenolol and Amlodipine Using Second Derivative Spectroscopy
}

\author{
Muharram Y. Mohammad ${ }^{1}$, Mohammad S. Abdullah" ${ }^{2 *}$, Sangar S. Sabir ${ }^{1}$ \\ ${ }^{1}$ Department of Medical Lab Technology, Erbil Medical Institute, Erbil Technical University, Kurdistan Region, Iraq, ${ }^{2}$ Department of Chemistry, \\ College of Education, Salahaddin-Erbil University, Kurdistan Region, Iraq
}

\author{
*Corresponding author: \\ Muharram Y. Mohammad, \\ Department of Medical Lab \\ Technology, Erbil Medical \\ Institute, Erbil Technical \\ University, Kurdistan Region, \\ Iraq. \\ E-mail: muharam. \\ mohammed@epu.edu.iq
}

Received: 11 October 2018

Accepted: 18 December 2018

Published: 30 October 2019

DOI

10.25156/ptj.v9n2y2019.pp25-29

\section{A B S T R A C T}

The present study describes employing second derivative spectrophotometry for the simultaneous determination of atenolol and amlodipine in pure form and in commercial formulations. The method is simple, accurate, precise, and economic. The zero-crossing point technique was used for analysis of the drugs in the combined formulation. The method was found to be linear in the concentration range of $5.0-50.0 \mu \mathrm{g} / \mathrm{ml}$ of atenolol at $251 \mathrm{~nm}$ and $5.0-45.0 \mu \mathrm{g} / \mathrm{ml}$ of amlodipine at $264 \mathrm{~nm}$. The proposed method was successfully applied to determine atenolol and amlodipine in combined dosage as well as in a separate dosage. The obtained results were in good agreement with standard method.

Keywords: Atenolol; Amlodipine; Second derivative spectroscopy

\section{INTRODUCTION}

Amlodipine besylate is a hypertensive drug with the chemical name of 3-ethyl 5-methyl (4RS)-2-[(2-aminoethoxy) methyl]-4-(2-chlorophenyl)-6-methyl-1,4-dihydropyridine3,5-dicarboxylate benzenesulfonate (Rahman and Azmi., 2000). It is calcium-channel blocker. Amlodipine is used for treatment of hypertension and angina pectoris (Ayad et al., 2012). Amlodipine acting by relaxation of the smooth muscle in arterial wall, decreasing total peripheral resistance and thus reducing blood pressure (Bhusari and Dhaneshwar, 2012). Atenolol chemically is 4-(2-hydroxy3 -isopropylaminopropoxy)-phenyl acetamide. It is a $\beta$-adrenoreceptor blocking agent. Atenolol is used mainly for angina pectoris, hypertension, and myocardial infarction (Pawar et al., 2013). The important function of atenolol in the human body is to stimulate the heart to beat more rapidly (Bhusari and Dhaneshwar, 2012). A combination between amlodipine and atenolol in pharmaceutical preparations has been introduced in the markets for hypertension treatment. Literature review reveals that methods have been reported for analysis of amlodipine and atenolol by derivative spectroscopy (Prasad et al., 1998; Kasture and Rameteke, 2006), simultaneous spectroscopic estimation (Jain and Agrawal, 2000; Patil et al., 2009; Godge et al., 2017), high-performance liquid chromatography (HPLC) (Halker et al., 1988; Shimooka et al., 1989; Yeung et al., 1991; Patki et al., 1994; Josefsson et al., 1995; Rahman et al., 2001), reversed-phase HPLC (RP-HPLC) (Ravishankar et al., 1997; Chitlange et al., 2009; Palani and Kamarapu, 2017), gas chromatography (Bresford et al., 1987), high-performance thin-layer chromatography (Agrekar and Powar, 2000), and voltammetry (Moraes et al., 2016) which were in individual formulations and combined dosage forms. Although the first derivative was used by Meghna et al., 2014 as well as the third derivative by Kasture and Ramteke, 2006 to estimate the two compounds simultaneously but the second derivative was not used for estimation of the two drugs together; therefore, the aim of this study is to develop analytical method for determination of atenolol and amlodipine in combined dose, using second derivative spectroscopy.

\section{MATERIALS AND METHODS}

\section{Apparatus}

A T80 + ultraviolet (UV)-visible spectrophotometer with $1.0 \mathrm{~cm}$ matched quartz cells was used for all spectral measurements.

\section{Chemicals}

Atenolol and amlodipine besylate standards were supplied by Awamedica Co. (Erbil, Iraq). 


\section{UV-derivative Spectroscopic Method}

Standard solutions of amlodipine and atenolol were scanned in the wavelength range of $200-400 \mathrm{~nm}$, using T80 + UV-visible spectrophotometer, with slow scan speed in absorbance measuring mode, and fixed interval $0.2 \mathrm{~nm}$, where distilled water was used as a reference. The spectrophotometer was connected with the computer, and the zero-order spectrum was converted to second derivative using 21 points derivative through UVWin5 Software (V5.2.0.1104), and no smoothing was required (Rathee et al., 2010).

\section{Preparation of Standard Solutions}

A $25 \mathrm{mg}$ of atenolol standard was weighed accurately and transferred to a beaker and dissolved in little amount of distilled water, then completed to $100 \mathrm{ml}$ with distilled water in a volumetric flask $(250 \mu \mathrm{g} / \mathrm{ml})$. A $34.665 \mathrm{mg}$ of amlodipine besylate equivalent to $25 \mathrm{mg}$ of amlodipine was weighed accurately and transferred to a beaker, then dissolved in little amount of distilled water and completed to $100 \mathrm{ml}$ with distilled water in a volumetric flask $(250 \mu \mathrm{g} / \mathrm{ml})$. The solutions of the drugs were stored in the refrigerator.

\section{Assay of Formulations}

Ten tablets of each brand were weighed and triturated into a fine powder. An amount of powder equivalent to one tablet was transferred into a beaker and dissolved with distilled water, then filtrated using Whatman no.1 filter paper. The precipitate on filter paper washed several times with distilled water and the washings were added to the filtrate. The volume of filtrate completed to $250 \mathrm{ml}$ in a volumetric flask using distilled water.

\section{RESULTS AND DISCUSSION}

The derivative spectrophotometry technique may be used for the determination of different compounds whose spectrum is overlapping with minimum error (Umapathi, 1994). The zero-order spectra of both drugs were found to be overlapping and each compound interferes with spectrophotometric determination of the other one [Figure 1]. It appears that atenolol has two maximum absorption bands at $225 \mathrm{~nm}$ and $274 \mathrm{~nm}$, while amlodipine has one maximum absorption band at $240 \mathrm{~nm}$ with shoulder.

The absorption of two or more compounds in the same wavelength region which would generate inseparable interference in normal spectrophotometry can be resolved using the derivative technique. The zero-crossing point method is used for this purpose. It is defined as a particular wavelength at which one component has a response (positive or negative), while the response of other drugs is zero. At zero crossing point, it is possible to measure the response of one component while the response of other remains zero, but for simultaneous determination of both drugs there must be two zero-crossing points at which one can be quantified while the response of the other would remain zero (Patel, 2013).

\section{Second Derivative Spectroscopy of Atenolol}

The second derivative spectroscopy of atenolol is shown in Figure 2. Atenolol has negative peak at $225.5 \mathrm{~nm}$ and positive peak at $238 \mathrm{~nm}$. The drug has more than one zero-crossing point, but the most useful one at $264 \mathrm{~nm}$ where the atenolol drug has zero absorbance for different concentrations.

\section{Second Derivative Spectroscopy of Amlodipine}

Figure 3 shows the second derivative spectroscopy of amlodipine concentrations. Amlodipine has two negative peaks at $214 \mathrm{~nm}$ and $240 \mathrm{~nm}$, with one positive peak at

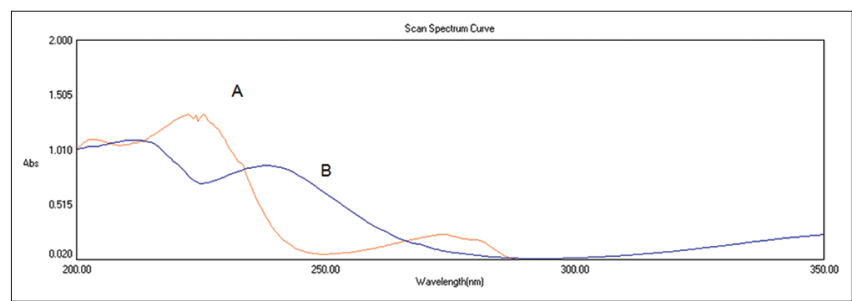

Figure 1: (A) Zero-order spectrum of $50 \mu \mathrm{g} / \mathrm{ml}$ atenolol (B) zeroorder spectrum of $20 \mu \mathrm{g} / \mathrm{ml}$ of amlodipine

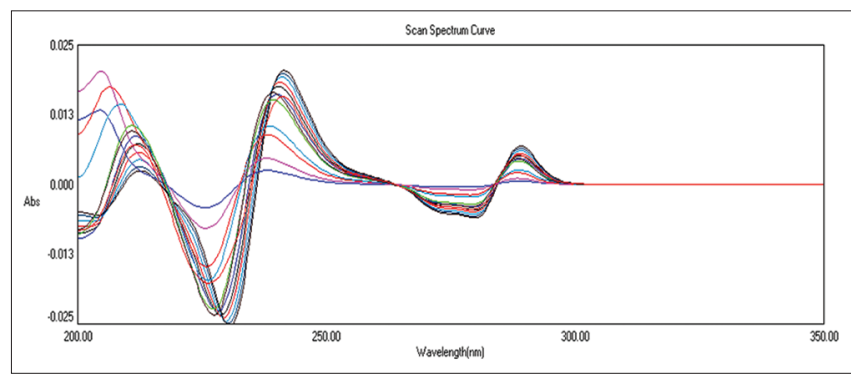

Figure 2: Second derivative spectroscopy of different concentration of atenolol $(5 \mu \mathrm{g} / \mathrm{ml}-\mu \mathrm{g} / \mathrm{ml})$

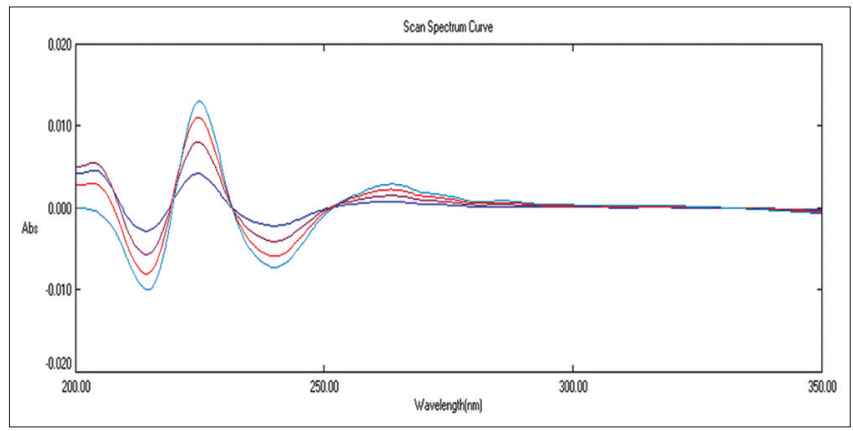

Figure 3: Second derivative spectroscopy of different conc. of amlodipine $(5 \mu \mathrm{g} / \mathrm{ml}-20 \mu \mathrm{g} / \mathrm{ml})$ 
$225 \mathrm{~nm}$. These peaks could be used to determine the drug when present alone. The drug has more than one zero crossing point but the most important is $251 \mathrm{~nm}$, where the $\mathrm{dA}^{2} / \mathrm{d}^{2} \lambda$ is zero at this wavelength. In the zero crossing derivative method, it is necessary that zerocrossing wavelengths do not change with changing the concentrations of the test analyte. To evaluate the condition, changes in the pre-mentioned zero-crossing wavelengths for amlodipine were tested. According to the results given in Figure 3, a shift in the zero-crossing wavelengths was observed beyond the concentration of $20 \mu \mathrm{g} / \mathrm{ml}$; hence, the determination of atenolol must be performed in the presence of $20 \mu \mathrm{g} / \mathrm{ml}$ of amlodipine or less.

Simultaneous Determination of Atenolol and Amlodipine Figure 4 shows the simultaneous determination of atenolol at $251 \mathrm{~nm}$ in the presence of $20 \mu \mathrm{g} / \mathrm{ml}$ amlodipine, where amlodipine has zero signals; therefore, it is possible to determine atenolol in combined dose. The atenolol was also determined at $251 \mathrm{~nm}$ in the presence of $5.0 \mu \mathrm{g} / \mathrm{ml}$ of amlodipine.

The simultaneous determination of amlodipine in the presence of $50 \mu \mathrm{g} / \mathrm{ml}$ atenolol at $264 \mathrm{~nm}$ is shown in Figure 5. The drug was determined in the presence of $50 \mu \mathrm{g} / \mathrm{ml}$ of atenolol, amlodipine may be determined even at higher concentration of atenolol because the latter zero-crossing point has not changed by the concentration, as depicted in Figure 2.

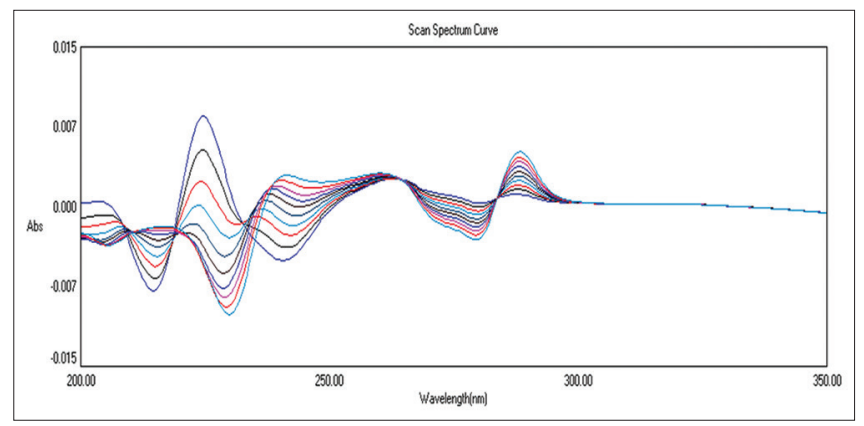

Figure 4: Simultaneous determination of atenolol at $251 \mathrm{~nm}$ in the presence of $20 \mu \mathrm{g} / \mathrm{ml}$ amlodipine

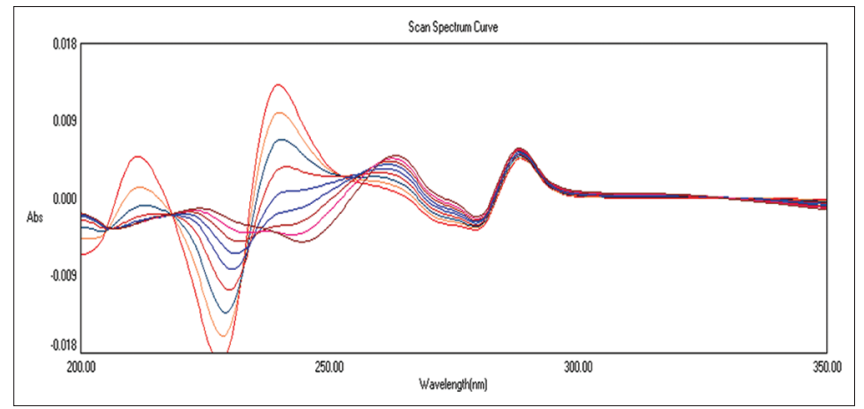

Figure 5: Simultaneous determination of amlodipine at $264 \mathrm{~nm}$ in the presence of $50 \mu \mathrm{g} / \mathrm{ml}$ atenolol
Determination of Atenolol Alone using Second Derivative Spectroscopy

For determination of atenolol, a good relation was found between the concentration of atenolol and peak amplitude at $225.5 \mathrm{~nm}$ and $238 \mathrm{~nm}$, using peak-to-baseline in measuring peak amplitude.

\section{Determination of Amlodipine Alone using Second Derivative Spectroscopy}

The determination of amlodipine was performed with the aid of the peak-to-base line in measuring peak height at $214 \mathrm{~nm}$ and $225 \mathrm{~nm}$, as shown in Figure 3.

\section{Calibration Graphs for Analysis of Atenolol and Amlodipine Simultaneously and Separately}

The calibration graphs were constructed between second derivative response and concentrations (Umapathi, 1994; Patel, 2013) for various series. All calibration graph parameters are tabulated in Table 1.

\section{Precision and Accuracy}

To check the precision of the proposed method, the pure drug solution at three different levels (different concentrations) were analyzed, each concentration being repeated 3 times. The relative standard deviation percentage was in the range of 1.19-2.62 to determine amlodipine in the presence of atenolol, and for determination of atenolol it was $0.81-4.81$ in the presence of amlodipine. The accuracy of the method was calculated through the recovery value [Table 2], and it was ranged from $94.23 \%$ to $103.4 \%$.

\section{Interference Study}

The influence of different compounds present in the commercial drugs on the determination of $25 \mu \mathrm{g} / \mathrm{ml}$ of atenolol and $25 \mu \mathrm{g} / \mathrm{ml}$ of amlodipine with second derivative spectrophotometry method were checked. The method was tolerable to $1000 \mu \mathrm{g} / \mathrm{ml}$ for each of glucose, cellulose, lactose, glycogen, sucrose, maltose, $\mathrm{KCl}$, and $\mathrm{NaCl}$, whereas it is tolerable to $250 \mu \mathrm{g} / \mathrm{ml}$ of each of fructose and starch. The relative error percentage was within $\pm 5.0 \%$.

\section{Method Application}

To evaluate the validity of the proposed work, atenolol and amlodipine were determined in some commercial drugs. The results of the determination of active ingredients in the commercial drugs are presented in Table 2. Atenolol was determined at $251 \mathrm{~nm}$ and amlodipine at $264 \mathrm{~nm}$ in the combined dose drugs as in the first three samples. The atenolol and amlodipine were individually estimated, using $225.5 \mathrm{~nm}$ and $238 \mathrm{~nm}$ for atenolol and the wavelengths of $214 \mathrm{~nm}$ and $225 \mathrm{~nm}$ were used for amlodipine estimation and the average contents are displayed in the next table. The results show good agreement between obtained results 
Table 1: Regression analysis of atenolol and amlodipine

\begin{tabular}{lccccc} 
Series $(\lambda)$ & \multicolumn{2}{c}{$\begin{array}{c}\text { Concentration } \\
(\lambda \mathrm{g} / \mathrm{ml})\end{array}$} & DL $(\mu \mathrm{g} / \mathrm{ml})$ & Regression equation & Correlation coefficient \\
\cline { 2 - 4 } & Atenolol & Amlodipine & & & \\
\hline A (264) & 50 & $5-45$ & 2.0 & $\mathrm{y}=0.0001 \mathrm{x}+0.0002$ & 0.9985 \\
B (251) & $5-50$ & 20.0 & 3.0 & $\mathrm{y}=7 \times 10^{-5} \times-0.0001$ & 0.9968 \\
C (251) & $5-50$ & 5.0 & 3.0 & $\mathrm{y}=6 \times 10^{-5} \times-5 \times 10^{-5}$ & 0.9996 \\
D (214) & 0.0 & $5-20$ & 2.0 & $\mathrm{y}=0.0005 \mathrm{x}+0.0008$ & 0.9944 \\
E (225) & 0.0 & $5-20$ & 1.0 & $\mathrm{y}=0.0006 \mathrm{x}+0.0017$ & 0.9944 \\
F (225.5) & $2-25$ & 0.0 & 1.0 & $\mathrm{y}=0.0007 \mathrm{x}+0.0009$ & 0.9951 \\
G (238) & $5-25$ & 0.0 & 2.0 & $\mathrm{y}=0.0004 \mathrm{x}+0.0004$ & 0.9985 \\
\hline
\end{tabular}

Table 2: Assay results of atenolol and amlodipine in commercial formulation by the proposed method

\begin{tabular}{|c|c|c|c|c|}
\hline Commercial name & Declared content (mg) & Found by proposed method (mg) & Found by HPLC method (mg) & Recovery \% \\
\hline \multicolumn{5}{|l|}{ Cipla } \\
\hline Atenolol & 50.0 & 47.87 & 48.50 & 98.70 \\
\hline Amlodipine & 5.0 & 5.10 & 4.93 & 103.4 \\
\hline \multicolumn{5}{|l|}{ Cipla } \\
\hline Atenolol & 25.0 & 24.40 & 24.20 & 100.82 \\
\hline Amlodipine & 5.0 & 4.90 & 5.20 & 94.23 \\
\hline \multicolumn{5}{|l|}{ Microlab } \\
\hline Atenolol & 50.0 & 53.10 & 52.50 & 101.11 \\
\hline Amlodipine & 5.0 & 4.90 & 5.17 & 94.77 \\
\hline \multicolumn{5}{|l|}{ Accord } \\
\hline Atenolol & 50.0 & 49.40 & 49.50 & 99.79 \\
\hline \multicolumn{5}{|l|}{ Amlong } \\
\hline Amlodipine & 5.0 & 4.75 & 4.86 & 97.73 \\
\hline
\end{tabular}

HPLC: High-performance liquid chromatography

by proposed method and that obtained by HPLC method (British Pharmacopoeia Commission, 2009).

\section{CONCLUSION}

The developed method for determination of atenolol and amlodipine was found to be simple, rapid, precise, and accurate. The derivative technique has succeeded in resolving the overlapped spectra and could be used for the simultaneous determination of each of atenolol and amlodipine drugs in combined dosage.

\section{REFERENCES}

Agrekar, A. P. and S. G. Powar. 2000. Simultaneous determination of atenolol and amlodipine in tablets by high performance thin layer chromatography. J. Pharm. Biomed. Anal. 21: 1137.

Ayad, M.M., H. E. Abdellatef, M. M. Hosny and Y. A. Sharaf. 2012. Spectrophotometric and Spectrofluorimetric Determination of amlodipine besylate and doxazosin mesilate in bulk and in dosage forms via hantzsch reaction. J. Int. J. Pharm. Biomed. Res. 3(2): 111-116.

Bhusari V. K. and S. R. Dhaneshwar. 2012. Validated HPTLC method for simultaneous estimation of atenolol and aspirin in bulk drug and formulation. J. Int. ISRN Anal. Chem. 2012: 609706.

Bresford, A. P., P. V. Marcrac and D. A. Stopher. 1987. Analysis of amlodipine in human plasma by gas chromatography. J. Chromatogr. 420: 178-183.
British Pharmacopoeia Commission. 2009. British Pharmacopeia The Stationery Office, London.

Chitlange, S., M. Imran and D. M. Sakarkar. 2009. RP-HPLC method for simultaneous estimation of amlodipine and metoprolol in tablet formulation. Asian J. Pharm. 2: 232-234.

Godge, R. K., G. S. Shinde and N. S. Dighe. 2017. Quantitative estimation and validation of atenolol and amlodipine besylate by absorbance ratio (Q) method. Eur. J. Pharm. Med. Res. 4(7): 412-415.

Halker, U. P., N. P. Bhandari and S. H. Rane. 1988. High performance liquid chromatographic simultaneous determination of amlodipine and enalapril maleate from pharmaceutical preparation. Indian Drugs. 35: 168-171.

Jain, H. K. and R. K. Agrawal. 2000. Spectroscopic methods for simultaneous determination of amlodipine besylate and lisinopril in tablets. Indian Drugs. 43: 111.

Josefsson, M., A. L. Zackrisson and B. Norlander. 1995. Sensitive high performance liquid chromatographic analysis of amlodipine in human plasma with amperometric detection and a single step solid phase sample preparation. J. Chromatogr. B Biomed. Appl. 672: 310-313.

Kasture, A. V. and M. Ramteke. 2006. Simultaneous UVspectrophotometric method for the estimation of atenolol and amlodipine besylate in combined dosage form. Indian J. Pharm. Sci. 68(3): 394-396.

Meghna, P. P., H. Raj and S. Nehal. 2014. First order derivative spectrophotometric method for simultaneous estimation of amlodipine besylate and indapamide in combined pharmaceutical dosage form. J. Asian J. Res. Chem. 7(7): 615-618.

Moraes, J. T., A. P. Eisele, C. A. R. Salamanca-Neto, J. Scremin and E. R. Sartori. 2016. Simultaneous voltammetric determination of antihypertensive drugs amlodipine and atenolol in 
pharmaceuticals using a cathodically pretreated boron-doped diamond electrode. J. Braz. Chem. Soc. 27(7); 1264-1272.

Palani, S. H. and S. K. Kamarapu. 2017. RP-HPLC method for the simultaneous estimation and validation of amlodipine besylate and atenolol in bulk and tablet dosage for biorelevant dissolution medium (Fassif). J. Res. J. Pharm. Technol. 10(10): 3379-3385.

Patel, A. 2013. Development validation of derivative spectoscopic method for simultaneous determination of nebivolol hydrochloride and S-amlodipine besylate in combined dosage. Int. J. Pharm. Biosci. 4(3): 379-391.

Patil, P. R., S. U. Rakesh, P. N. Dhabale and K. B. Burade. 2009. Simultaneous UV spectrophotomtric method for estimation of losartan potassium and amlodipine besylate in tablet dosage form. Asian J. Res. Chem. 2(1): 183-187.

Patki, R. V., C. P. Tamhanker and H. P. Tipnis.1994. Simple and rapid high performance liquid chromatographic estimation of amlodipine in pharmaceutical dosage forms. Indian Drugs. 31: $560-561$.

Pawar, P. A., B. Y. Mane, S. M. Auti. and V. V. Trivedi. 2013. Simultaneous estimation of atenolol and amlodipine besylate in tablets formulations by Vierodt's method using U.V spectrophotometry. Pharm. Chem. 5(2): 97-102.

Prasad, C. V., Parihar, C. and T. R. Chowdhary. 1998. Simultaneous determination of atenolol amlodipine and haloperidol trihexaphenidyl in combined tablet preparations by derivative spectroscopy. Pharm. Pharmacol. Commun. 4(7): 325-330.
Rahman, N. and S. N. H. Azmi. 2000 Spectrophotometric determination of amlodipine besylate by charge transfer complex formation with P-chloranilic acid. J. Jpn. Soc. Anal. Chem. 16: 1353-1356.

Rahman, N., S. Najmul and H. Azmi. 2001. Spectrophotometric method for the determination of amlodipine besylate with ninhydrin in drug formulation. Farmaco. 56(10): 731-735.

Rathee, P., S. Rathee, S. Thakur and V. Kumar. 2010. Simultaneous estimation of amlodipine besylate and lisinopril dihydrate as A.P.I. and in tablet dosage forms by modified form of simultaneous equation method using derivative UV spectrophotometry. Int. J. Pharm. Tech. Res. 2(1): 556-562.

Ravishankar, S., M. J. Nanjan, M. Vasudevan, N. Shaat and B. Suresh. 1997. Simultaneous estimation of atenolol and amlodipine in formulation by reversed phase-HPLC. Ind. J. Pharm. Sci. 59: 171-173.

Shimooka, K., Y. Sawada and H. Tatematsu. 1989. Analysis of amlodipine by a sensitive high performance liquid chromatography method with amperometric detection. J. Pharm. Biomed. Anal. 7: 1267-1272.

Umapathi, P. 1994. Determination of atenolol, nifedipine, aspirin and dipyridamole in tablet preparations by second-order derivative spectrophometry. Int. J. Pharm. 108(1): 11-19.

Yeung, P. K., S. J. Mosher and P. T. Pollack. 1991. High performance liquid chromatography assay for amlodipine: Chemical stability and pharmacokinetics in rabbits. J. Pharm. Biomed. Anal. 9: 565-571. 